\title{
Effect of Cognitive-Behavioral Therapy on Neural Correlates of Fear Conditioning in Panic Disorder
}

\author{
Tilo Kircher, Volker Arolt, Andreas Jansen, Martin Pyka, Isabelle Reinhardt, Thilo \\ Kellermann, Carsten Konrad, Ulrike Lueken, Andrew T. Gloster, Alexander L. Gerlach, \\ Andreas Ströhle, André Wittmann, Bettina Pfleiderer, Hans-Ulrich Wittchen, and Benjamin \\ Straube
}

\begin{abstract}
Background: Learning by conditioning is a key ability of animals and humans for acquiring novel behavior necessary for survival in a changing environment. Aberrant conditioning has been considered a crucial factor in the etiology and maintenance of panic disorder with agoraphobia (PD/A). Cognitivebehavioral therapy (CBT) is an effective treatment for PD/A. However, the neural mechanisms underlying the effects of $\mathrm{CBT}$ on conditioning processes in $\mathrm{PD} / \mathrm{A}$ are unknown.
\end{abstract}

Methods: In a randomized, controlled, multicenter clinical trial in medication-free patients with PD/A who were treated with 12 sessions of manualized CBT, functional magnetic resonance imaging (fMRI) was used during fear conditioning before and after CBT. Quality-controlled fMRI data from 42 patients and 42 healthy subjects were obtained.

Results: After CBT, patients compared to control subjects revealed reduced activation for the conditioned response (CS+> CS-) in the left inferior frontal gyrus (IFG). This activation reduction was correlated with reduction in agoraphobic symptoms from t1 to t2. Patients compared to control subjects also demonstrated increased connectivity between the IFG and regions of the "fear network" (amygdalae, insulae, anterior cingulate cortex) across time.

Conclusions: This study demonstrates the link between cerebral correlates of cognitive (IFG) and emotional ("fear network") processing during symptom improvement across time in PD/A. Further research along this line has promising potential to support the development and further optimization of targeted treatments.

Key Words: Agoraphobia, CBT, fear conditioning, fMRI, functional connectivity, neural plasticity, panic disorder

Panic disorder is a debilitating anxiety disorder with a lifetime prevalence of approximately $3 \%$ to $5 \%$. It is characterized by intermittent and sudden extreme anxiety, vegetative symptoms, and concerns about the implications of the attacks. Agoraphobia, the anticipatory anxiety or avoidance of situations in which escape or help may not be available in case of panic symptoms, is a frequent consequence (1). An interaction of biological vulnerability $(2,3)$, learning history and acute stress underlies the etiology of panic disorder with agoraphobia (PD/A) (4-6). Cognitive-behavioral therapy (CBT) and/or selective serotonin reuptake inhibitors are effective first-line treatments for $\mathrm{PD} / \mathrm{A}(4,7)$.

The onset and continuation of some anxiety disorders, particularly panic disorder, has been linked to aberrant learning (conditioning) processes $(5,8-10)$. Fear conditioning is a form of associative learning in which contingencies are established by pairing aversive stimuli 
(unconditioned stimulus [US]) with previously neutral stimuli (conditioned stimulus [CS]). Brain imaging studies have related fear conditioning to a neural network including the amygdalae (11-14), insulae (14), anterior cingulate cortex (ACC) (14), and medial frontal gyrus ("fear network") $(13,15)$. This network has substantial overlap with fear circuitry structures that have been reported to show aberrant activation in different anxiety disorders $(16,17)$. Studies with functional magnetic resonance imaging (fMRI) in patients with panic disorder have implicated the amygdala, anterior insula, ACC, and medial frontal gyrus in the disorder (15), supporting the role of the "fear network" in its pathophysiology $(13,15)$. However, with regard to fear conditioning in PD/A, to our knowledge only one imaging study has been conducted so far. Increased activity with regard to the CS- had been observed in the amygdala, subgenual cingulate, and midbrain structures using an instructed fear paradigm (18).

Whereas the neural correlates of treatment effects on patients with specific phobia $(19,20)$ or obsessive-compulsive disorder (21) have been investigated in a number of studies (see Porto et al. [22] and Linden [23] for reviews), the neural mechanisms underlying PD/A and its potential changes through CBT remain largely unknown. To date, only two positron emission tomography (PET) studies have examined the modulation of brain physiology with CBT in PD using a resting state paradigm $(24,25)$. In the first study, the CBT group (6 patients) showed decreases in regions of the right inferior temporal and superior and inferior frontal gyrus (IFG), and increases were detected in the left IFG, middle temporal gyrus, and insula (25). In the other PET study, 11 patients with PD who improved after CBT were investigated (24). Here, glucose utilization increased in the bilateral medial prefrontal cortices and decreased in the right hippocampus, left ACC, left cerebellum, and pons. Thus, these studies provide first support for CBT modulating brain activation in $\mathrm{PD}$, most consistently in frontal brain regions. However, it is unknown how these changes in brain activation during rest are related to processes associated with panic disorder, such as conditioning.

Particular regions within the frontal cortex might be relevant for the psychopathology $(18,26,27)$ and its treatment of $\mathrm{PD} / \mathrm{A}(15)$. Medial and orbitofrontal brain regions are associated with emotion regulation/reduction and provide direct connections to the amygdala. The lateral prefrontal cortex and specifically the left inferior frontal gyrus/sulcus (Brodmann area 44$)$, which is indirectly linked to the amygdala $(28,29)$, is implicated in voluntary increase of emotions and anticipation of panic attacks (30,31). Thus, cognitions are able to increase or decrease emotional responses efficiently (32). Correspondingly, positive, negative, or bidirectional associations between frontal activity and activation of the fear network have been demonstrated (28,33-37). However, it is unknown whether patients with PD/A suffer either from a lack of cognitive control over normal emotional responses or from negative cognitions which trigger or amplify extreme emotional reactions.

In this fMRI study, we investigated the influence of CBT on the neural correlates of fear conditioning in $\mathrm{PD} / \mathrm{A}$. We hypothesized that $\mathrm{CBT}$ will modify activation during fear acquisition in regions of the prefrontal cortex and the "fear network". Whereas the applied fear conditioning paradigm should probe automatic fear learning mechanisms predominantly in the "fear network" (amygdalae, hippocampi, anterior insulae, ACC), we expected that CBT will primarily act on negative cognitions triggered by conditioned stimuli in PD/A patients. The neural correlates of negative cognitions (e.g., selective attention to threat) are assumed to be related to the left lateral frontal cortex. Whereas reduction of activation in "fear network" areas as a result of symptom improvement are likely, there were two possible result patterns for regions of the prefrontal lobe: increased prefrontal activation after CBT would indicate compensation or reappraisal processes, whereas decreased activity would rather speak for a 
reduction of negative cognitions. Consequently two result patterns can be assumed for the connectivity between frontal regions ("cognitive processes") activated during fear conditioning and the "fear network" ("emotional processes") in PD/A. A negative connectivity would indicate inhibition or reappraisal processes, whereas a positive correlation would rather suggest that negative cognitions trigger emotional responses.

\section{Methods and Materials}

\section{Participants}

The present study was part of the national research network PANIC-NET $(7,38,39)$ encompassing a randomized controlled clinical trial on CBT and experimental add-on studies on fear circuit mechanisms in PD/A. Eight German centers participated in the clinical trial (Aachen, Berlin-Adlershof, Berlin-Charité, Bremen, Dresden, Greifswald, Münster, Würzburg) treating 369 patients who met DSM-IV criteria for PD/A. Four of these centers (Aachen, Berlin- Charité, Dresden, Münster) also participated in the fMRI study reported here.

In the context of the fMRI part of the clinical multicenter study (38), quality controlled fMRI data (for details of the procedure, see Supplement 1) were collected 8 weeks apart from 42 unmedicated patients with PD/A before and after CBT as well as 42 healthy control subjects matched for age, gender, and handedness (40) (see Table 1 and Figure S1 in Supplement 1). For a description of the applied clinical assessments as well as inclusion and exclusion criteria, see Supplement 1 and $(7,38)$. After a complete description of the study protocol, written informed consent was obtained from every participant and the protocol was approved by the local ethics committees in each fMRI center according to the Declaration of Helsinki.

\section{Procedure: Treatment and Clinical Assessment}

CBT was administered in 12 twice-weekly sessions based on a highly standardized and controlled treatment protocol (see Supplement 1 Information and Gloster et al. [7,38]). PD/A patients were randomly assigned to two versions of CBT, which differed only in therapistguided or non-therapist-guided exposure sessions (sessions 6-8 and 9-11). Because both groups received a comparable treatment and demonstrated significant symptom reduction after CBT (7), groups were collapsed in the current study.

In addition to those assessments of the clinical trial, cognitive abilities were assessed using Trail Making Test A and B (TMT-A/B) and digit span.

Paradigm-specific behavioral data were collected before fMRI data acquisition for the US (aversiveness rating at $\mathrm{t} 1$; from 0 not aversive to 10 very aversive) and during fMRI data acquisition for both conditioned stimuli (CS+ and $\mathrm{CS}-$ ) at three time points: after the familiarization, after the acquisition and after the extinction phase using the Self-Assessment Manikin (SAM) (41), with a 5-point Likert scale $(1=$ very unpleasant to $5=$ very pleasant and $1=$ not arousing to $5=$ very arousing). Behavioral data of the acquisition phase are given in the result section. The complete rating data were provided in Supplement 1 (Table S2).

$f M R I$

Parallel versions of a previously validated differential conditioning paradigm were applied during MRI data acquisition (Figure 1) (41) before and after CBT. All patients and control 
subjects were measured at the same fMRI scanner at $\mathrm{t} 1$ and $\mathrm{t} 2$. In the fMRI analysis (discussed below), we compared the difference between CS + and CS- across $\mathrm{t} 1$ and $\mathrm{t} 2$ to examine the therapy-related changes of the conditioning processes.

\section{fMRI Data Acquisition and Preprocessing}

fMRI brain images were acquired using 3T Philips Achieva scanners (Philips Medical Systems, Best, The Netherlands) in Münster and Aachen, a 3T Siemens Trio scanner (Siemens AG, Erlangen, Germany) in Dresden, and a 3T General Electric Healthcare scanner (General Electric Healthcare, Milwaukee, Wisconsin) in Berlin.Atotal of 505 transaxial functional images (echo-planar images, $64 \times 64,30$ slices interleaved, field of view $=230$, voxel size $=3.6 \times 3.6 \times 3.8 \mathrm{~mm}$, echo time $=30 \mathrm{msec}$, repetition time $=2 \mathrm{sec})$ that covered the whole brain and were positioned parallel to the intercomissural line (anterior commissureposterior commissure) were recorded.

Magnetic resonance images were analyzed using Statistical Parametric Mapping (SPM5; www.fil.ion.ucl.ac.uk) implemented in MATLAB 7.1 (Mathworks, Sherborn, Massachusetts). The first five volumes of every functional run were discarded to minimize t1 saturation effects. For data preprocessing, standard slice-timing (middle slice), realignment and normalizing $\left(2 \times 2 \times 2 \mathrm{~mm}^{3}\right)$ functions of SPM5 were applied. To account for differences in intrinsic smoothness between scanners, an iterative smoothness equalization (42) procedure was performed for all data sets using an target smoothness of 12-mm full width at half maximum Gaussian isotropic kernel. Thus, data from all centers have been iteratively smoothed until a smoothness of $12-\mathrm{mm}$ full width at half maximum was reached, independent of scanner-specific intrinsic smoothness of the data. Finally, the quality $(43,44)$ of the acquired data was carefully checked to avoid systematic differences between the patient and control groups (Supplement 1).

\section{Single Subject fMRI Analyses}

At the single-subject level, the realignment parameters of each participant were included as regressors into the model to account for movement artifacts of the participants. The blood oxygen level-dependent (BOLD) response for each event type (CS+paired, CS+unpaired, CS, US) and each phase (F1, F2, A1, A2, E1, E2; see Figure 1) was modeled by the canonical hemodynamic response function employed by SPM5 within the framework of the general linear model to analyse brain activation differences related to the onset of the different stimuli. Each phase was separated into an early and a late part to account for temporal aspects and habituation (45), resulting in 16 regressors (familiarization: early $\mathrm{CS}+$, late $\mathrm{CS}+$; early CS-, late CS-; US; acquisition: early CS-, late CS-, CS presented with the US (CS+paired); US; early CS+ without US (CS+unpaired), late CS+unpaired; extinction: early CS-, late CS-; early CS+, late CS+; behavioral assessment).

A high-pass filter (128-sec cutoff period) was applied to remove low frequency fluctuations in the BOLD signal. Parameter estimates $(\beta)$ and $t$ statistic images were calculated for each subject.

\section{Connectivity Analyses}

For the connectivity analyses, eigenvectors adjusted for the effect of movement parameters were extracted from the entire IFG cluster (identified in the group analysis) on a singlesubject level across the whole experiment (500 scans). The individual eigenvectors were used 
as regressors in new single-subject analyses that additionally included the six movement regressors. We obtained individual activation maps reflecting the correlation of each voxel time course with the time course of the left IFG as outcomes for each time point and group. These images were used in the group analyses (flexible factorial analyses) focusing on the main effects and interactions of group and time.

\section{Group Analyses}

Random effects group analyses were performed by entering contrast images into flexible factorial analyses as implemented in SPM5, in which subjects are treated as random variables. The fMRI center was introduced as a covariate to account for scanner differences. Further covariates of no interest included education level, for which we found group differences, and the depression score (Beck Depression Inventory-II) that might be confounded with panicspecific treatment effects in the current sample. Other variables, such as age, gender, and aversiveness rating, had been checked. However, they did not significantly change our results.

A Monte Carlo simulation of the brain volume of the current study was conducted to establish an appropriate voxel contiguity threshold (46). The calculation of the cluster size to correct for multiple comparisons is based on algorithms that accounted for the difference of original and normalized cluster sizes as well as smoothing kernel and total volume of data acquisition $(47,48)$. Assuming an individual voxel type I error of $p<.005$, a cluster extent of 142 contiguous resampled voxels $\left(1136 \mathrm{~mm}^{3}\right)$ was indicated as sufficient to correct for multiple voxel comparisons at $\mathrm{p}<.05$. Thus, voxels with a significance level of $\mathrm{p}<.005$ uncorrected belonging to clusters with at least 142 voxels $\left(1136 \mathrm{~mm}^{3}\right)$ were reported for all analyses.

For the left IFG cluster, percent signal change was extracted separately for each stimulus class. Percent signal change was calculated by applying the MarsBaR (http://marsbar.sourceforge.net) toolbox for SPM.

\section{Results}

\section{Clinical Improvement}

Results of the clinical trial in a much larger patient sample, which demonstrate the efficiency of the CBT treatment, are reported elsewhere in detail (7). In the smaller subgroup of patients who participated in our fMRI study, we obtained a significant reduction of symptoms after therapy (e.g., Clinical Global Impressions Scale; Hamilton Anxiety Scale; Panic and Agoraphobia Scale; Anxiety Sensitivity Index; 7-day version of the Mobility Inventory; Table 1), which supports the efficiency of the CBT treatment in this study.

\section{Behavioral Results of the Conditioning Experiment}

The rating of valence and arousal with regard to the stimuli (CS+ and CS-, respectively) that were acquired after the acquisition phase (41) (Figure 1) support the validity of our paradigm in demonstrating a main effect of condition for valence [CS- $>\mathrm{CS}+; \mathrm{F}(1,80)=12.481, \mathrm{p}=$ .001 ; partial eta squared $=.135]$ and arousal $[\mathrm{CS}+>\mathrm{CS}-; \mathrm{F}(1,80)=11.767, \mathrm{p}=.001$; partial eta squared $=.128]$ in an analysis of variance. Thus, the conditioned stimulus (CS+) was evaluated as less positive (low valence) and more arousing (high arousal) than the control stimulus (CS-). The significant effect of group indicates general lower ratings of valence $[\mathrm{P}<$ $\mathrm{C} ; \mathrm{F}(1,80)=7.677, \mathrm{p}=.007$; partial-eta squared $=.088)$ and higher ratings of arousal for patients in contrast to the control group $[\mathrm{P}>\mathrm{C} ; \mathrm{F}(1,80)=9.060, \mathrm{p}=.003$; partial eta squared $=$ 
.102]. The effect of time point was significant for valance ratings only [valence: $\mathrm{t} 1<\mathrm{t} 2$; $\mathrm{F}(1,80)=4.495, \mathrm{p}=.037$; partial eta squared $=.053$; arousal: $\mathrm{F}(1,80)=2.383, \mathrm{p}=.127$; partial eta squared $=.029]$. However, the interaction of group and time point; group and condition; or group, time point, and condition for both valence and arousal did not reach significance (all ps $>.10)$.

\section{fMRI Results}

For the effect of CBT on the conditioned response (CS+unpaired $>\mathrm{CS}-$ ) in the patient versus the control group (interaction group $\times$ time), wefound activation of the left IFG extending into the anterior insula (Figure 2). Importantly, this effect was already present in the early phase of fear acquisition (A1; Figure 1) (45). Post hoc analyses indicate that this interaction effect was driven by a significant activation reduction $(\mathrm{t} 1>\mathrm{t} 2)$ in the patient group (Figure $\mathrm{S} 2$ in Supplement 1). This reduction in BOLD signal from t 1 to $t 2$ was correlated with reduction in agoraphobic symptoms from $t 1$ to $t 2$ (Mobility Inventory (38), a main outcome measure of the clinical trial (7); Spearman's rho: $r=.353 ; \mathrm{p}<.05$ corrected for multiple comparisons). Correlations with the other outcome measures (Hamilton Anxiety Scale, Clinical Global Impressions Scale, or number of panic attacks) were not significant (Table S3 in Supplement 1), indicating a specific relation to agoraphobic avoidance. The same fMRI analyses performed for the other experimental phases (F1, F2, A2, E1, E2; Figure 1) and the opposite contrasts $(\mathrm{CS}+<\mathrm{CS}-)$ did not show any significant activation (except for a nonpredicted single cluster in the parietal lobe for $\mathrm{C}>\mathrm{P}$ in $\mathrm{A} 2$ ). When analyzing the two groups ( $\mathrm{P}$ and $\mathrm{C}$ ) separately across time $(\mathrm{t} 1>\mathrm{t} 2)$, we found a reduced conditioned response $(\mathrm{CS}+>\mathrm{CS}-)$ at $\mathrm{t} 2$ in the left amygdala, insula, the bilateral basal ganglia, and the ACC ("fear network") (13) for the patient but not the control group (Table 2). For further main effects as well as the effects of the US, see Figure S3 and S4 in Supplement 1.

\section{Connectivity Analyses}

We found a significant main effect for group $(\mathrm{P} / \mathrm{C})$, indicating a higher functional connectivity in patients $(\mathrm{P}>\mathrm{C})$ between the left IFG and the bilateral amygdalae, the hippocampi, the ACC, and the medial and lateral PFCs (Figure 3). There was no significant interaction effect across group and time ( $\mathrm{t} 1 / \mathrm{t} 2)$.

To explore the clinical relevance of the left IFG connectivity analyses, we included the main outcome measures from the clinical trial (7) predefined before the start of the study (Hamilton Anxiety Scale, Clinical Global Impressions Scale, number of panic attacks [PA], and the Mobility Inventory scores) as covariate of interest in the analyses. First, we explored the effect of the covariates on IFG connectivity at $\mathrm{t} 1$ and in a second step for $\mathrm{t} 2$ (for both $\mathrm{F}$ contrasts across all outcome measures were calculated). At $t 1$, we found a significant effect in the left amygdala expanding in the temporal pole and hippocampus (Montreal Neurological Institute [MNI] xyz $\left.[-28,4,-24] ; \mathrm{F}=6.28, \mathrm{p}<.001,3504 \mathrm{~mm}^{3}\right)$. Contrast estimates indicated that this effect is predominantly driven by a positive correlation especially for PA and Mobility Inventory (as more panic attacks and agoraphobic symptoms a patient had at $\mathrm{t} 1$ as stronger was the connectivity between the left IFG and the left amygdala; Supplement 1). At $\mathrm{t} 2$, we found significant effects of the clinical scores in the bilateral and medial frontal cortices (left: MNI xyz $[-32,52,26] ; \mathrm{F}=5.10, \mathrm{p}<.001,6008 \mathrm{~mm}^{3}$; and MNI xyz $[-32,24$, $32] ; \mathrm{F}=5.03, \mathrm{p}<.001,1448 \mathrm{~mm}^{3}$; right: MNI xyz [30,48,8]; $\mathrm{F}=5.31, \mathrm{p}<.001,8872 \mathrm{~mm}^{3}$ ) as well as the anterior, middle, and posterior cingulate cortex (ACC: MNI xyz $[-16,52,-8] ; \mathrm{F}$ $=4.92, \mathrm{p}<.001,2176 \mathrm{~mm}^{3}$ and MNI xyz $[18,50,-6] ; \mathrm{F}=5.10, \mathrm{p}<.001,1496 \mathrm{~mm}^{3}$; MCC: MNI xyz $\left.[-8,30,24] ; \mathrm{F}=4.32, \mathrm{p}<.001,1552 \mathrm{~mm}^{3}\right)$; PCC: MNI xyz $[-10,-52,30] ; \mathrm{F}=5.48$, 
$\mathrm{p}<.001,2632 \mathrm{~mm}^{3}$ ). The negative contrast estimates at $\mathrm{t} 2$ for PA and MI7ac indicated a negative correlation between symptom severity (panic attacks and agoraphobic avoidance) and connectivity of the left IFG to the respective regions (Supplement 1).

\section{Discussion}

Panic disorder with agoraphobia is a debilitating and costly anxiety disorder $(4,49)$ that is being treated effectively with CBT (7). Here, we demonstrate the effect of CBT on the neural networks of fear conditioning in patients with $\mathrm{PD} / \mathrm{A}$. As a main result, the interaction analyses demonstrated the left IFG to be involved in the pathology and successful psychotherapy of panic disorder (Figure 2).

Evidence from research in animals and humans suggest a so-called fear network $(13,15)$ including the amygdala $(11,12,14,15,50)$, insula $(12,43,51)$, ACC (14), and medial frontal brain regions (11) to be involved in fear conditioning as well as panic disorder $(13,15)$. Even if not significant in the interaction analysis, we found an activation reduction in these brain regions after therapy in patients, indicating a significant influence of psychotherapy on brain pathophysiology in key areas of fear processing. By contrast, in the control group, we obtained activation predominantly in the pre- and postcentral gyri including inferior and superior parts of the parietal cortex (Table 2), which might reflect a reduction of attention with regard to $\mathrm{CS}+$ at the second time point.

Whereas the amygdala and insula have been related to negative emotional responses, the dorsal and rostral anterior cingulate cortices and the ventromedial prefrontal cortex have been connected to the experience and regulation of emotions (16,52). Regarding the insular cortex, a functional gradient from the posterior to the anterior insula has been described (53). It has been argued that anxiety disorders are predominantly reflected by altered information processing in the anterior insula $(51,52)$. The amygdala plays a central role in the subjective feeling of fear $(11,54)$. The pre-post comparison in our patient sample $(\mathrm{t} 1>\mathrm{t} 2)$ indicates a reduced activation of the amygdala, bilateral anterior insula, as well as parts of the dorsal and rostral anterior cingulate cortices and the ventromedial PFC. Thus, one might speculate that the reduction of activity in the amygdala and insula reflect attenuated negative emotional responses. The medial frontal and anterior cingulate activation may further reflect a reduced experience or regulation of anxiety after CBT.

In contrast to these putative emotional processes related to fear network activation, the left IFG is involved primarily in cognitive functions (e.g., attention, execution control, reasoning, verbalization). Especially for panic disorder and its treatment, cognitive processes are highly relevant, because even conditioning processes and exposure therapy have been assumed to involve strong cognitive components (see Hofmann [55] for a review). Thus, our data indicate that cognitive processes (IFG) are tightly associated with the aberrant emotional responses (fear network) and the pathophysiology and treatment of panic disorder. This interpretation is in line with studies suggesting the frontal cortex being involved in negative cognitions such as worries or rumination, connected to an emotional state (56). Furthermore evidence from instructed fear in healthy subjects suggests an involvement of the left IFG in cognitions related to negative affect (30). Correspondingly, there is evidence that aversive imagery in $\mathrm{PD} / \mathrm{A}$ increases physiologic reactions such as heart beat and startle reflex (57).

We found increased IFG activation before therapy that is normalized by CBT. These results suggest that CBT reduces negative cognitions, such as increased harm expectancy (55) or attention to threat (58), related to the frontal cortex, which indicate aversive contingencies and 
consecutively activate the fear network. Our connectivity analysis further supports this interpretation and demonstrates the increased connection of the IFG with regions of the fear network in $\mathrm{PD} / \mathrm{A}$, suggesting an increased association of cognitive and emotional processes within the patient compared to the control group. Thus, cognitive processes might trigger emotional responses related to fear network activity more easily in patients with PD/A than in control subjects. This interpretation is supported by the positive correlation of the left IFG connectivity with the clinical outcome measures, which indicates that patients with higher rates of panic attacks and agoraphobic symptoms (MI7) had also a stronger connectivity between the left IFG and the left amygdala at $t 1$.

Despite the significant reduction of IFG activity after CBT, there was no change in functional connectivity across time in both groups. Thus, changes of connectivity might be more difficult to obtain or will be established only after a longer period. An alternative explanation would be that an increased coupling between the left IFG and regions of the fear network might represent a specific vulnerability ("trait") for $\mathrm{PD} / \mathrm{A}$, but this needs to be confirmed by further longitudinal studies.

Consistent with the two resting state positron emission tomography studies that have examined the modulation of brain physiology with CBT in PD $(24,25)$, we could demonstrate an effect of $\mathrm{CBT}$ on neural mechanisms in $\mathrm{PD} / \mathrm{A}$. However, results are quite heterogeneous (as noted earlier), probably because of differences in the imaging method (positron emission tomography vs. $\mathrm{fMRI}$ ), in sample size $-\mathrm{n}=6(25), \mathrm{n}=12(24), \mathrm{n}=42$ our study - and especially different paradigms (resting state vs. fear conditioning).

However, effects of CBT on activity in regions of the fear network have been also demonstrated in other disorders such as schizophrenia (59) and depression (60). For example, in line with our results, effects of CBT on the IFG, insula, thalamus, putamen, and occipital areas had been shown (59). Intriguingly Fu and colleagues could show a significant positive association between clinical outcome and linear load-response activity (increasingly sad faces) in the left IFG (Brodmann's area 44), as depressed patients with the largest clinical response showed the highest linear load-response in this region at baseline (60). Although CBT treatment protocols and disorders of these studies are different, these findings support the role of the (left) IFG in CBT. In line with the interpretation of Kumari et al. (59), our data suggest that CBT may mediate symptom reduction by promoting processing of threats in a less distressing way.

Our findings should be interpreted within the methodologic limitations of this study. First, there is no group of patients receiving a control intervention. Therefore, our effects might not necessarily be specific to CBT and could potentially also be induced by other psychotherapeutic methods $(61,62)$, pharmacotherapy (25) or spontaneous remission. Thus, future studies are needed to shed further light on the effects of different (psychotherapeutic) treatments on brain processes. Second, comorbid depression was not excluded per se because its presence conforms to the usual picture seen in practice and may thus improve external validity of the sample. However, in our fMRI analyses, we controlled for depression scores (Beck Depression Inventory-II), which also improved in light of CBT (63). Finally, to disentangle bottom up from top-down processes relevant in PD/A and exposure-based CBT, the inclusion of cognitive regulation tasks could be helpful in future investigations. 


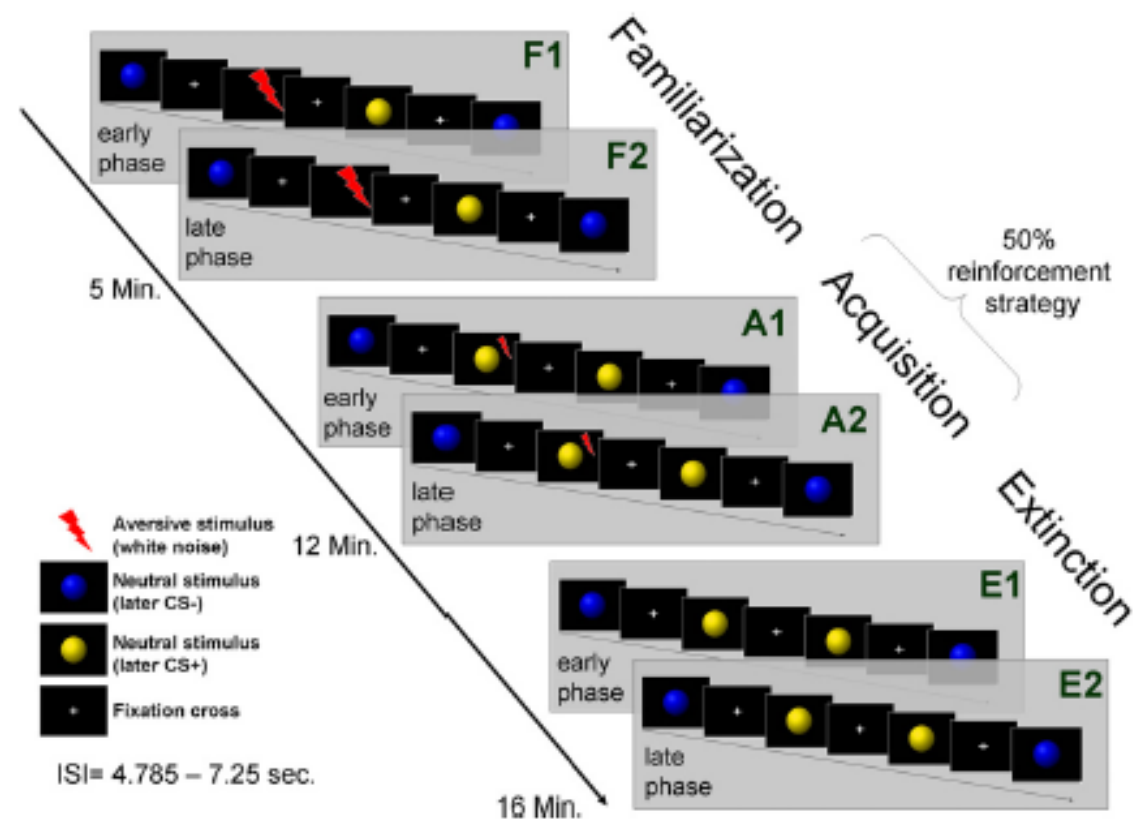

Figure 1. The conditioning paradigm. The time course of the functional magnetic resonance imaging (fmRI) paradigm consisted of three phasesfamiliarization (F), acquisition (A), and extinction (E) (41)_each subdivided into an early and a late phase (45). Different neutral stimuli (yellow/blue spheres and violet/green squares) were used in parallel versions to account for repeated exposure to the experiment in the pre-post design (time point $t 1$, $t 2$ ). Each sphere/square was visually presented for $2000 \mathrm{msec}$ with a varlable interstimulus interval (ISI) of 4.785 to 7.250 sec. An unpleasant white nolse was used as the unconditioned stimulus (US) and presented for $100 \mathrm{msec}$. The volume of the US was Indlvidually adapted (between 70 and $110 \mathrm{~dB}$ ) to be unpleasant for the participant. The same individual adapted volume level of this first measurement was also used for the second measurement ( $(2)$ ). During the acquisition phase, one sphere/square was palred pseudo-randomlywith the US (thus becoming conditioned stimulus [CS] +], and the other sphere was not (thus becoming CS-1. We used a partial reinforcement strategy in which $50 \%$ of the CS + were paired with the US, and $50 \%$ were not. Only those trials in which no US was delivered were analyzed during acquisition to avold overlap with neuronal activation directly related to the presentation of the US. The presentation of the US occurred 1900 msec after the onset of the CS + , which is why both stimull coterminated. The US was not presented during the extinction phase. The sultability of the paradigm is supported by a pllot study in healthy subjects (41).

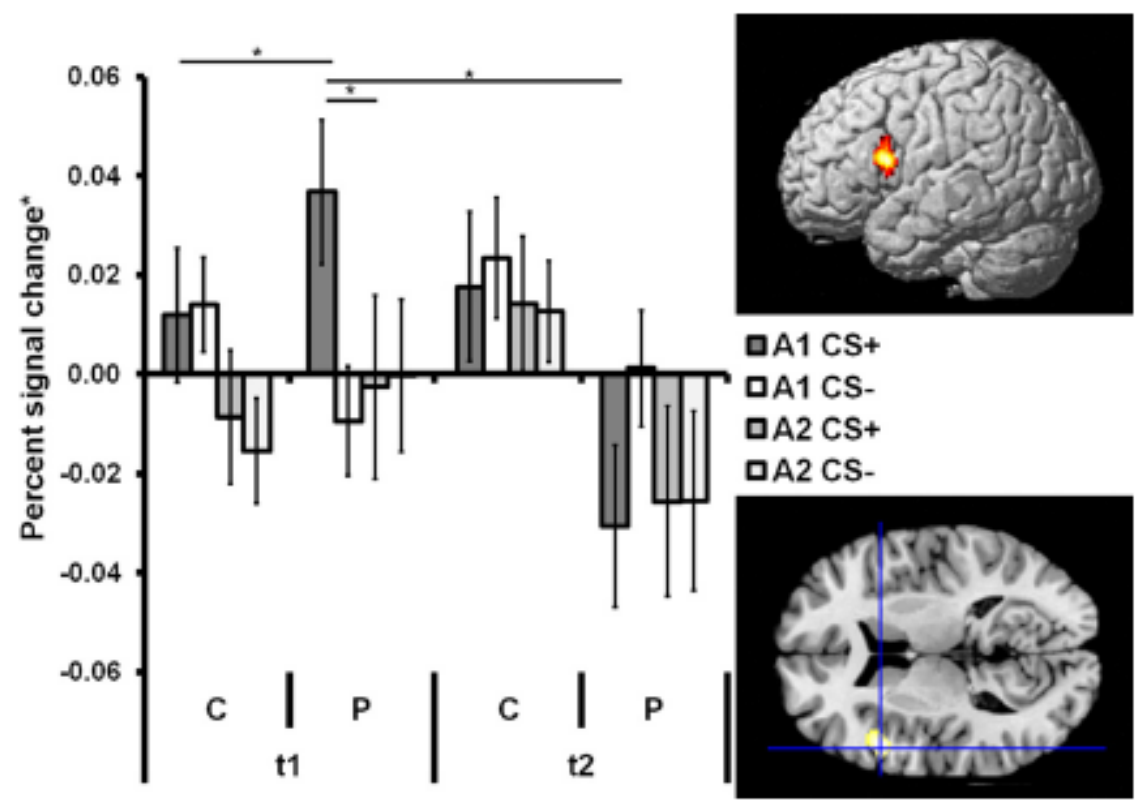

Figure 2. Interaction of activation for group (P/C), time point (t1/t2), and stimulus type (conditioned stimulus [CS] +/CS-) during early acquisition (A1; Supplement 1 and Table 2). The results were specific to early acquisition phase (A1) and did not occur in any of the other 5 experimental phases (Figure $S 2$ in Supplement 1). Error bars refer to the standard error of the mean. 


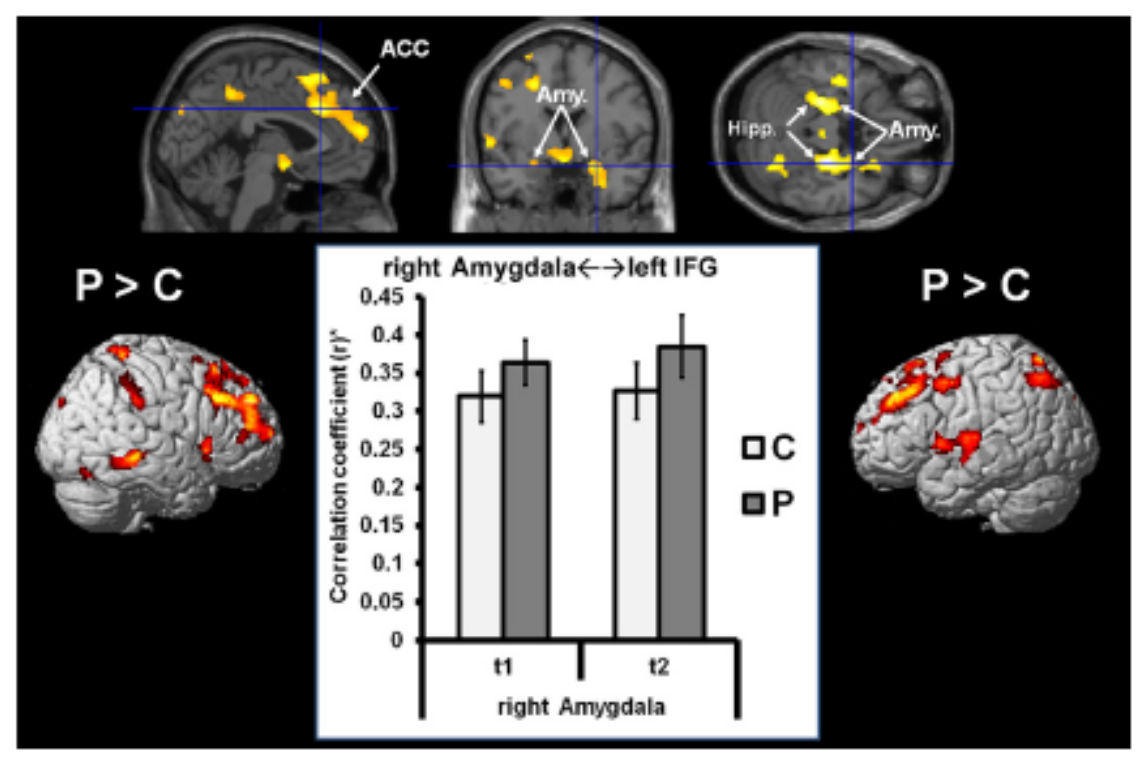

Figure 3. Group difference (P > Q in the connectivity of the left Inferior frontal gyrus (IFG). Connectivity was analyzed across the whole time course of the conditioning paradigm. The activation cluster of the left IFG (Flgure 2) served as the seed reglon. We found a significant main effect for "group," Indicating a higher functional connectivity in patlents (P > C) between the left IFG and the bilateral amygdalae (Amy.), the hippocampl (Hipp.), the anterlor cingulate cortex (ACC), and the medial and lateral prefrontal cortex (PFC; fear network). The bar graph illustrates the correlation coefficlents for the correlation between the left IFG and the right amygdala. Correlation coefficlents were obtained by correlating extracted single subject time-course data of the left IFG (defined by the group analysis) and the right amygdala (defined by the use of the anatomy toolbox) (64). The interaction of "group" and "time point" as well as changes in connectlivity across "time" (separately for the patlent and control groups) did not reach significance.

Table 1. Demographic and Clinical Characteristics

\begin{tabular}{|c|c|c|c|c|}
\hline & fMRI PD/A Sample $(n-42)$ & fMRI Control Sample $(n-42)$ & $\chi^{2} \pi t$ & $p$ \\
\hline \multicolumn{5}{|c|}{ Demographic Characteristics } \\
\hline Female gender, $n$ (\%6) & $29(699 \%)$ & $29(6996)$ & $<.001$ & $>.999$ \\
\hline \multicolumn{5}{|l|}{ Education (years), $n$ (16) } \\
\hline 8 & $3(7 \%)$ & $2(596)$ & 6.329 & .042 \\
\hline 10 & $18(4396)$ & $8(1996)$ & & \\
\hline $12-13$ & $21(5096)$ & $32(7696)$ & & \\
\hline Age (years) & $35.42(32.25-3.8 .59)$ & $34.33(31.26-37.41)$ & -.496 & .621 \\
\hline \multicolumn{5}{|c|}{ Neuropsychological Characteristics } \\
\hline Digit span Forward & $7.81(7.19-8.43)$ & $8.52(7.95-9.10)$ & 1.714 & .090 \\
\hline Diglt span Backward & $7.26(6.65-7.87)$ & $6.95(6.33-7.57)$ & -.720 & .473 \\
\hline TMT-A (sec) & $25.60(22.99-28.21)$ & $25.35(22.76-27.95)$ & -.136 & .892 \\
\hline TMT-8 (sec) & $55.40(50.37-60.42)$ & $52.52(47.16-57.89)$ & -.788 & .433 \\
\hline \multicolumn{5}{|c|}{ Clinical Characteristics at Baseline (time point 1) } \\
\hline HAM-A total & $24.38(22.70-26.07)$ & & & \\
\hline CGI & $5.36(5.16-5.55)$ & & & \\
\hline No. of PA & $1.67(1.41-1.92)$ & & & \\
\hline MI7 & $2.12(1.84-2.40)$ & & & \\
\hline MI7 acc. & $1.85(1.57-2.13)$ & & & \\
\hline Mr7 alone & $2.39(2.07-2.70)$ & & & \\
\hline PAS total & $25.97(23.27-28.68)$ & & & \\
\hline ASI total & $31.10(28.18-34.01)$ & $8.64(6.41-10.87)$ & -12.342 & $<.001$ \\
\hline BDI II total & $17.26(14.37-20.15)$ & $1.37(.76-1.98)$ & -10.740 & $<.001$ \\
\hline \multicolumn{5}{|c|}{ No. of Comorbid Dlagnosis, $n$ (96) } \\
\hline None & $11(2696)$ & & & \\
\hline 1 & $15(36 \%)$ & & & \\
\hline 2 & $5(12 \%)$ & & & \\
\hline 3 & $6(14 \%)$ & & & \\
\hline$>3$ & $5(12 \%)$ & & & \\
\hline \multicolumn{5}{|c|}{ Clinical Characteristic at Posttreatment (time point 2) } \\
\hline HAM-A total & $12.36(10.21-14.51)$ & & & \\
\hline CGl & $3.55(3.22-3.87)$ & & & \\
\hline No. of PA & $.90(61-1.20)$ & & & \\
\hline MI7 & $1.49(1.32-1.67)$ & & & \\
\hline Mi7 acc. & $1.33(1.17-1.49)$ & & & \\
\hline Mi7 alone & $1.66(1.42-1.89)$ & & & \\
\hline PAS total & $13.95(11.28-16.63)$ & & & \\
\hline ASI total & $15.48(12.80-18.16)$ & $7.69(5.68-9.69)$ & -4.552 & $<.001$ \\
\hline BDI II total & $9.05(6.65-11.44)$ & $.76(.14-1.38)$ & -6.140 & $<.001$ \\
\hline
\end{tabular}

Numbers in parentheses refer to the $95 \%$ confidence interval, except for gender, years of education and number of comorbid diagnosis where numbers refer to percentages. $\chi^{2}$, $t$ and $p$ values refer to group comparisons of the respective variables. fMRI sample, patients with quality-controlled fMRI data. The patients who participated in the fMRi experiment did not differ in any of the sociodemographic or clinical variables from the clinical sample; see ( 7 ).

ASI, Anxlety Sensitivity Index; BDI II, Beck Depression Inventory-ll; CGI, Clinical Global Impressions Scale; fMRi, functional magnetic resonance Imaging; HAM-A, Hamilton Anxlety Scale; MI7, 7-day verslon of the Mobility Inventory (as total score as well as separated in the alone and accompanled version, see [7]); PA, panic attack; PAS, Panic and Agoraphobla Scale; PD/A, panic disorder with agoraphobla; TMT-A, Trall Making Test A; TMT-B, Trall Making Test $B$. 
Table 2. Actlivation Peaks and Cluster Extenslons for Activation Reduction (t1 > 2) of the Conditioned Response (CS + > CS-) Separate for Patlents and Control Subjects

\begin{tabular}{|c|c|c|c|c|c|c|c|}
\hline \multirow[b]{2}{*}{ Anatomic Reglon } & \multirow[b]{2}{*}{ Cluster Extent } & \multicolumn{3}{|c|}{ Coordinates } & \multirow[b]{2}{*}{ t Value } & \multirow[b]{2}{*}{$p$ Value } & \multirow[b]{2}{*}{ Volume $\left(\mathrm{mm}^{2}\right)$} \\
\hline & & $\mathrm{x}$ & y & z & & & \\
\hline \multicolumn{8}{|l|}{ Patlents $(t 1>t 2)$} \\
\hline Left IFG & Left precentral gyrus, insula & -46 & 12 & 14 & 4.65 & $<.001$ & 17424 \\
\hline Left ACC & Medial frontal cortex superior frontal cortex & -32 & -2 & -12 & 4.18 & $<.001$ & 18824 \\
\hline Left amygdala & $\begin{array}{l}\text { Left Insula, putamen, pallidum, thalamus, } \\
\text { temporal lobe }\end{array}$ & -10 & 46 & -2 & 4.07 & $<.001$ & 26128 \\
\hline Right MFG & Right dlPFC, superior frontal cortex & 46 & 4 & -36 & 3.69 & $<.001$ & 1384 \\
\hline Right IFG & $\begin{array}{l}\text { Right precentral gyrus, insula, rolandic } \\
\text { operculum }\end{array}$ & 56 & 36 & 12 & 3.54 & $<.001$ & 6304 \\
\hline Right BG & $\begin{array}{l}\text { Right nucleus caudatus, putamen, pallidum, } \\
\text { thalamus }\end{array}$ & 12 & 6 & 12 & 3.10 & .001 & 2224 \\
\hline \multicolumn{8}{|l|}{ Controls $(t 1>t 2)$} \\
\hline Plght precentral gyrus & $\begin{array}{l}\text { Right postcentral gyrus, Inferior and } \\
\text { superior parletal cortex }\end{array}$ & 22 & -32 & 70 & 4.04 & $<.001$ & 4480 \\
\hline Left postcentral gyrus & $\begin{array}{l}\text { Left paracentral lobe, precentral gyrus, } \\
\text { precuneus }\end{array}$ & -22 & -32 & 70 & 3.72 & $<.001$ & 4016 \\
\hline Right nucleus caudatus & Left nucleus caudatus & 4 & 12 & 10 & 3.49 & $<.001$ & 2664 \\
\hline Left PCC & Left and right MCC & -2 & -34 & 30 & 3.43 & $<.001$ & 1584 \\
\hline Left SMA & Left MCC, paracentral lobule & -10 & -8 & 52 & 3.34 & $<.001$ & 1976 \\
\hline Left fusiform gyrus & $\begin{array}{l}\text { Left Inferior temporal gyrus, } \\
\text { parahippocampus, cerebellum }\end{array}$ & -42 & -42 & -22 & 3.15 & .001 & 1760 \\
\hline \multicolumn{8}{|c|}{ Interaction, Patlent vs. Control Group } \\
\hline Left IFG & Left anterior Insula & -50 & 10 & 14 & 3.19 & .001 & 1776 \\
\hline
\end{tabular}

Significance level, $t$ values, uncorrected $p$ value, and the size of the respective volume of activated cluster $\left(\mathrm{mm}^{2}\right)$ at $p<.05$, corrected $($ Monte Carlo simulation), were mentioned. Coordinates are listed in Montreal Neurological instltute atlas space. Cluster extensions denominate activated reglons for larger voxel clusters encompassing different brain areas and should be considered approximate.

ACC, anterior cingulate cortex; BG, basal ganglia; IFG, Inferior frontal gyrus; MCC, middle cingulate cortex MFG, middle frontal gyrus; PCC, posterior cingulate cortex; dIPFC, dorsolateral prefrontal cortex; SMA, supplemental motor area; $t 1$, time point 1; t2, time point 2 .

This study provides evidence about the link between the cerebral correlates of cognitive and emotional processing in interaction with CBT in patients with panic disorder. On the basis of these findings, we are confident that further research in this line has promising potential to support the development and further optimization of targeted treatments.

This work is part of the German multicenter trial "Mechanisms of Action in CBT (MAC)." The MAC study is funded by the German Federal Ministry of Education and Research (Project No. 01GV0615) as part of the Psychotherapy Research Funding Initiative.

Centers: principal investigators (PIS) with respective areas of responsibility in the MAC study are V. Arolt (Münster: Overall MAC Program Coordination), H.U. Wittchen (Dresden: PI for the Randomised Clinical Trial [RCT ] and Manual Development), A. Hamm (Greifswald: PI for Psychophysiology), A.L. Gerlach (Münster: PI for Psychophysiology and Panic subtypes), A. Ströhle (Berlin: PI for Experimental Pharmacology), T. Kircher (Marburg: PI for Functional Neuroimaging), and J. Deckert (Würzburg: PI for Genetics). Additional site directors in the RCT component of the program are G.W. Alpers (Würzburg), T. Fydrich and L. Fehm (Berlin-Adlershof), and T. Lang (Bremen).

Data access and responsibility: All PIs take responsibility for the integrity of the respective study data and their components. All authors and co-authors had full access to all study data.

Acknowledgements and staff members by site: Greifswald (coordinating site for psychophysiology): Christiane Melzig, Jan Richter, Susan Richter, Matthias von Rad; BerlinCharite (coordinating centre for experimental pharmacology): Harald Bruhn, Anja Siegmund, Meline Stoy, Andre Wittmann; Berlin-Adlershof: Irene Schulz; Münster (Overall MAC Program Coordination, Genetics and Functional Neuroimaging): Andreas Behnken, Katharina Domschke, Adrianna Ewert, Carsten Konrad, Bettina Pfleiderer, Christiana Sehlmeyer, Peter Zwanzger; Münster (coordinating site for psychophysiology and subtyping): 
Judith Eidecker, Swantje Koller, Fred Rist, Anna Vossbeck-Elsebusch; Marburg/Aachen (coordinating centre for functional neuroimaging): Barbara Drüke, Sonja Eskens, Thomas Forkmann, Siegfried Gauggel, Susan Gruber, Andreas Jansen, Thilo Kellermann, Isabelle Reinhardt, Nina Vercamer-Fabri; Dresden (coordinating site for data collection, analysis, andthe RCT): Franziska Einsle, Christine Fröhlich, Andrew T. Gloster, Christina Hauke, Simone Heinze, Michael Höfler, Ulrike Lueken, Peter Neudeck, Stephanie Preiß, Dorte Westphal; Würzburg Psychiatry Department (coordinating centre for genetics): Andreas Reif; Würzburg Psychology Department: Julia Dürner, Hedwig Eisenbarth, Antje B. M. Gerdes, Harald Krebs, Paul Pauli, Silvia Schad, Nina Steinhäuser; Bremen: Veronika Bamann, Sylvia Helbig-Lang, Anne Kordt, Pia Ley, Franz Petermann, Eva-Maria Schröder. Additional support was provided by the coordinating centre for clinical studies in Dresden (KKS Dresden): Xina Grählert and Marko Käppler.

The randomized clinical trial project was approved by the Ethics Committee of the Medical Faculty of the Technical University of Dresden (EK 164082006). The neuroimaging components were approved by the Ethics Committee of the Medical Faculty of the RheinischWestfälische Hochschule University Aachen (EK 073/07). The experimental pharmacology study was approved by the Ethics Committee of the state of Berlin (EudraCT: 2006-00-486029).

Professor Volker Arolt is member of the advisory boards and/or gave presentations for the following companies: Astra-Zeneca, Janssen-Organon, Lilly, Lundbeck, Servier, Pfizer, and Wyeth. He chaired the committee for the Wyeth Research Award Depression and Anxiety. Professor Tilo Kircher has received in the past 3 years honoraria or educational grants from Janssen, Bristol Myers-Squibb, Wyeth, Lundbeck, Lilly, Astra-Zeneca, and Pfizer. Andreas Jansen, Martin Pyka, Isabelle Reinhardt, Thilo Kellermann, Carsten Konrad, Ulrike Lueken, Andrew T. Gloster, Alexander L. Gerlach, Andreas Ströhle, André Wittmann, Bettina Pfleiderer, Hans-Ulrich Wittchen, and Benjamin Straube reported no biomedical financial interests or potential conflicts of interest.

International Standard Randomised Controlled Trials Number (ISRCTN): Improving cognitive behavioural therapy for panic by identifying the active ingredients and understanding the mechanisms of action: a multicentre study; http://www.controlledtrials.com/ISRCTN80046034/ISRCTN80046034.

Supplementary material cited in this article is available online.

1. Wittchen HU, Jacobi F (2005): Size and burden of mental disorders in Europe-a critical review and appraisal of 27 studies. Eur Neuropsychopharmacol 15:357-376.

2. Domschke K, Braun M, Ohrmann P, Suslow T, Kugel H, Bauer J, et al. (2006): Association of the functional $-1019 \mathrm{C} / \mathrm{G}$ 5-HT1A polymorphism with prefrontal cortex and amygdala activation measured with $3 \mathrm{~T}$ fMRI in panic disorder. Int J Neuropsychopharmacol 9:349-355. 3. Hettema JM, Neale MC, Kendler KS (2001):Areview and meta-analysis of the genetic epidemiology of anxiety disorders. Am J Psychiatry 158: 1568-1578.

4. Roy-Byrne PP, Craske MG, Stein MB (2006): Panic disorder. Lancet 368: 1023-1032. 5. Bouton ME, Mineka S, Barlow DH (2001): A modern learning theory perspective on the etiology of panic disorder. Psychol Rev 108:4-32.

6. Richter J, Hamm AO, Pané-Farré CA, Gerlach AL, Gloster AT, Wittchen H-U, et al. (2012): Dynamics of defensive reactivity in patients with panic disorder and agoraphobia: Implications for the etiology of panic disorder [published online ahead of print May 22]. Biol Psychiatry. 
7. Gloster AT, Wittchen HU, Einsle F, Lang T, Helbig-Lang S, Fydrich T, et al. (2011): Psychological treatment for panic disorder with agoraphobia: A randomized controlled trial to examine the role of therapist-guided exposure in situ in CBT. J Consult Clin Psychol 79:406420.

8. Lissek S, Powers AS, McClure EB, Phelps EA, Woldehawariat G, Grillon C, et al. (2005): Classical fear conditioning in the anxiety disorders: A meta-analysis. Behav Res Ther 43:1391-1424.

9. Grillon C, Lissek S, McDowell D, Levenson J, Pine DS (2007): Reduction of trace but not delay eyeblink conditioning in panic disorder.AmJ Psychiatry 164:283-289.

10. Lissek S, Rabin S, Heller RE, Lukenbaugh D, Geraci M, Pine DS, et al. (2010): Overgeneralization of conditioned fear as a pathogenic marker of panic disorder. Am J Psychiatry 167:47-55.

11. Alvarez RP, Biggs A, Chen G, Pine DS, Grillon C (2008): Contextual fear conditioning in humans: Cortical-hippocampal and amygdala contributions. JNeurosci 28:6211-6219.

12. Buchel C, Dolan RJ, Armony JL, Friston KJ (1999): Amygdala-hippocampal involvement in human aversive trace conditioning revealed through event-related functional magnetic resonance imaging. J Neurosci 19:10869-10876.

13. Gorman JM, Kent JM, Sullivan GM, Coplan JD (2000): Neuroanatomical hypothesis of panic disorder, revised. Am J Psychiatry 157:493-505.

14. Sehlmeyer C, Schoning S, Zwitserlood P, Pfleiderer B, Kircher T, Arolt V, et al. (2009): Human fear conditioning and extinction in neuroimaging: A systematic review. PLoSOne 4:e5865.

15. de Carvalho MR, Dias GP, Cosci F, de-Melo-Neto VL, Bevilaqua MC, Gardino PF, et al. (2010): Current findings of fMRI in panic disorder: Contributions for the fear neurocircuitry and CBT effects. Expert Rev Neurother 10:291-303.

16. Etkin A, Wager TD (2007): Functional neuroimaging of anxiety: A metaanalysis of emotional processing in PTSD, social anxiety disorder, and specific phobia. Am J Psychiatry 164:1476-1488.

17. Shin LM, Liberzon I (2010): The neurocircuitry of fear, stress, and anxiety disorders. Neuropsychopharmacology 35:169-191.

18. Tuescher O, Protopopescu X, Pan H, Cloitre M, Butler T, Goldstein M, et al. (2011): Differential activity of subgenual cingulate and brainstem in panic disorder and PTSD. $J$ Anxiety Disord 25:251-257.

19. Schienle A, Schafer A, Stark R, Vaitl D (2009): Long-term effects of cognitive behavior therapy on brain activation in spider phobia. Psychiatry Res 172:99-102.

20. Goossens L, Sunaert S, Peeters R, Griez EJ, Schruers KR (2007): Amygdala hyperfunction in phobic fear normalizes after exposure. Biol Psychiatry 62:1119-1125. 21. Freyer T, Klöppel S, Tüscher O, Kordon A, Zurowski B, Kuelz AK, et al. (2011): Frontostriatal activation in patients with obsessive-compulsive disorder before and after cognitive behavioral therapy. Psychol Med 41:207-216.

22. Porto PR, Oliveira L, Mari J, Volchan E, Figueira I, Ventura P (2009): Does cognitive behavioral therapy change the brain? A systematic review of neuroimaging in anxiety disorders. J Neuropsychiatry Clin Neurosci 21: 114-125.

23. Linden DE (2008): Brain imaging and psychotherapy: Methodological considerations and practical implications. Eur Arch Psychiatry Clin Neurosci 258(suppl 5):71-75.

24. Sakai Y, Kumano H, Nishikawa M, Sakano Y, Kaiya H, Imabayashi E, et al. (2006): Changes in cerebral glucose utilization in patients with panic disorder treated with cognitivebehavioral therapy. Neuroimage 33: 218-226.

25. Prasko J, Horacek J, Zalesky R, Kopecek M, Novak T, Paskova B, et al. (2004): The change of regional brain metabolism (18FDG PET) in panic disorder during the treatment with cognitive behavioral therapy or antidepressants. Neuro Endocrinol Lett 25:340-348. 
26. Pillay SS, Rogowska J, Gruber SA, Simpson N, Yurgelun-Todd DA (2007): Recognition of happy facial affect in panic disorder: An fMRI study. J Anxiety Disord 21:381-393. 27. Pillay SS, Gruber SA, Rogowska J, Simpson N, Yurgelun-Todd DA (2006): fMRI of fearful facial affect recognition in panic disorder: The cingulate gyrus-amygdala connection. $\mathrm{J}$ Affect Disord 94:173-181.

28. Zhou Z, Ding M, Chen Y, Wright P, Lu Z, Liu Y (2009): Detecting directional influence in fMRI connectivity analysis using PCA based Granger causality. Brain Res 1289:22-29. 29. Pessoa L (2008): On the relationship between emotion and cognition. Nat Rev Neurosci 9:148-158.

30. Urry HL, van Reekum CM, Johnstone T, Kalin NH, Thurow ME, Schaefer HS, et al. (2006): Amygdala and ventromedial prefrontal cortex are inversely coupled during regulation of negative affect and predict the diurnal pattern of cortisol secretion among older adults. $\mathrm{J}$ Neurosci 26:4415-4425.

31. Bystritsky A, Pontillo D, Powers M, Sabb FW, Craske MG, Bookheimer SY (2001): Functional MRI changes during panic anticipation and imagery exposure. Neuroreport 12:3953-3957.

32. Ochsner KN, Ray RD, Cooper JC, Robertson ER, Chopra S, Gabrieli JD, et al. (2004): For better or for worse: neural systems supporting the cognitive down- and up-regulation of negative emotion. Neuroimage 23:483-499.

33. Winecoff A, Labar KS, Madden DJ, Cabeza R, Huettel SA (2011): Cognitive and neural contributors to emotion regulation in aging. Soc Cogn Affect Neurosci 6:165-176.

34. Liu CC, Crone NE, Franaszczuk PJ, Cheng DT, Schretlen DS, Lenz FA (2011): Fear conditioning is associated with dynamic directed functional interactions between and within the human amygdala, hippocampus, and frontal lobe. Neuroscience 189:359-369.

35. Banks SJ, Eddy KT, Angstadt M, Nathan PJ, Phan KL (2007): Amygdalafrontal connectivity during emotion regulation. Soc Cogn Affect Neurosci 2:303-312.

36. Curcic-Blake B, Swart M, AlemanA(2012): Bidirectional information flow in frontoamygdalar circuits in humans: a dynamic causal modeling study of emotional associative learning. Cereb Cortex 22:436-445.

37. Jabbi M, Keysers C (2008): Inferior frontal gyrus activity triggers anterior insula response to emotional facial expressions. Emotion 8:775-780.

38. Gloster AT, Wittchen HU, Einsle F, Hofler M, Lang T, Helbig-Lang S, et al. (2009): Mechanism of action in CBT (MAC): methods of a multi-center randomized controlled trial in 369 patients with panic disorder and agoraphobia. Eur Arch Psychiatry Clin Neurosci 259:155-166.

39. Arolt V, Zwanzger P, Strohle A, Hamm A, Gerlach A, Kircher T, et al. (2009): [The research network PANIC-NET: Improving the treatment of panic disorder-from a better understanding of fear circuit mechanisms to more effective psychological treatment and routine care]. Psychother Psychosom Med Psychol 59:124-131.

40. Oldfield RC (1971): The assessment and analysis of handedness: The Edinburgh inventory. Neuropsychologia 9:97-113.

41. Reinhardt I, Jansen A, Kellermann T, Schüppen A, Kohn N, Gerlach AL, et al. (2010):

Neural correlates of aversive conditioning: Development of a functional imaging paradigm for the investigation of anxiety disorders. Eur Arch Psychiatry Clin Neurosci 260:443-453.

42. Friedman L, Glover GH, Krenz D, Magnotta V, Birn F (2006): Reducing inter-scanner variability of activation in a multicenter fMRI study: Role of smoothness equalization. Neuroimage 32:1656-1668.

43. Stocker T, Schneider F, Klein M, Habel U, Kellermann T, Zilles K, et al. (2005): Automated quality assurance routines for fMRI data applied to a multicenter study. Hum Brain Mapp 25:237-246. 
44. Friedman L, Glover GH (2006): Reducing interscanner variability of activation in a multicenter fMRI study: Controlling for signal-to-fluctuation-noise- ratio (SFNR) differences. Neuroimage. 33:471-481.

45. Büchel C, Morris J, Dolan RJ, Friston KJ (1998): Brain systems mediating aversive conditioning: An event-related fMRI study. Neuron 20:947-957.

46. Forman SD, Cohen JD, Fitzgerald M, Eddy WF, Mintun MA, Noll DC (1995): Improved assessment of significant activation in functional magnetic resonance imaging (fMRI): Use of a cluster-size threshold. Magn Reson Med 33:636-647.

47. Slotnick SD, Moo LR, Segal JB, Hart J Jr (2003): Distinct prefrontal cortex activity associated with item memory and source memory for visual shapes. Brain Res Cogn Brain Res 17:75-82.

48. Slotnick SD. Scripts and stimuli. Available at: https://www2.bc.edu/ slotnics/scripts.htm. 49. Katon WJ (2006): Clinical practice. Panic disorder. N Engl J Med. 354: 2360-2367.

50. Ciocchi S, Herry C, Grenier F, Wolff SB, Letzkus JJ, Vlachos I, et al. (2010): Encoding of conditioned fear in central amygdala inhibitory circuits. Nature 468:277-282.

51. Paulus MP, Stein MB (2006): An insular view of anxiety. Biol Psychiatry 60:383-387.

52. Etkin A, Egner T, Kalisch R (2011): Emotional processing in anterior cingulate and medial prefrontal cortex. Trends Cogn Sci 15:85-93.

53. CraigAD(2009):Howdo you feel-now? The anterior insula and human awareness. Nat Rev Neurosci 10:59-70.

54. Rauch SL, Shin LM, Wright CI (2003): Neuroimaging studies of amygdala function in anxiety disorders. Ann N Y Acad Sci 985:389-410.

55. Hofmann SG (2008): Cognitive processes during fear acquisition and extinction in animals and humans: Implications for exposure therapy of anxiety disorders. Clin Psychol Rev 28:199-210.

56. Berkowitz RL, Coplan JD, Reddy DP, Gorman JM (2007): The human dimension: How the prefrontal cortex modulates the subcortical fear response. Rev Neurosci 18:191-207.

57. McTeague LM, Lang PJ, Laplante MC, Bradley MM (2011): Aversive imagery in panic disorder: Agoraphobia severity, comorbidity, and defensive physiology. Biol Psychiatry 70:415-424.

58. Bishop SJ (2008): Neural mechanisms underlying selective attention to threat. Ann N Y Acad Sci 1129:141-152.

59. Kumari V, Fannon D, Peters ER, Ffytche DH, Sumich AL, Premkumar P, et al. (2011): Neural changes following cognitive behaviour therapy for psychosis: A longitudinal study. Brain 134:2396-2407.

60. Fu CH, Williams SC, Cleare AJ, Scott J, Mitterschiffthaler MT, Walsh ND, et al. (2008):

Neural responses to sad facial expressions in major depression following cognitive behavioral therapy. Biol Psychiatry 64:505-512.

61. Milrod B, Leon AC, Busch F, Rudden M, Schwalberg M, Clarkin J, et al. (2007): A randomized controlled clinical trial of psychoanalytic psychotherapy for panic disorder. Am J Psychiatry 164:265-272.

62. Beutel ME, Stark R, Pan H, Silbersweig D, Dietrich S (2010): Changes of brain activation pre- post short-term psychodynamic inpatient psychotherapy: AnfMRI study of panic disorder patients. Psychiatry Res 184:96-104.

63. Emmrich A, Beesdo-Baum K, Gloster AT, Knappe S, Höfler M, Arolt V, et al. (2012):

Depression does not affect the treatment outcome of CBT for panic and agoraphobia: Results from a multicenter randomized trial. Psychother Psychosom 81:161-172.

64. Amunts K, Kedo O, Kindler M, Pieperhoff P, Mohlberg H, Shah NJ, et al. (2005):

Cytoarchitectonic mapping of the human amygdala, hippocampal region and entorhinal cortex: Intersubject variability and probability maps. Anat Embryol (Berl) 210:343-352. 